\title{
Unsettling Languages, Unruly Bodyminds: Imaging a Crip Linguistics
}

\section{Plain Language Abstract}

People use languages in different ways. Some people use language to help find other people like them. Many people use language in specific ways because of how their body and mind work. Sometimes a person's environment and material conditions forces them to use language in a certain way. However, when someone languages outside of what people think is normal, others can think that they are bad with language or are not as smart or are broken. We are trying to point out that no one is actually 'bad with language.' Our goal with this paper is to help people understand that no language is bad. It is okay to want to change your own language use if it will make you feel better. But no one should make you feel bad about your language. We need a bigger and more flexible understanding of what language is and what it communicates about a bodymind's capacity.

\section{Keywords}

Crip linguistics, disability, languaging, multi-modality 
Jon Henner

Octavian Robinson

\section{Introduction}

In 2020, a conspiracy sped across the TikTok scene. Helen Keller could not possibly have existed nor successfully learned to communicate if she indeed was both deaf and blind. As a deaf and blind person, it was difficult for people to conceive Keller as someone who had language. Journalist Rebecca Onion (2021) wrote of the conspiracy, it was "not a deficit of knowledge, but an active contestation of it". The core argument made by Keller conspiracy theorists was that if a person could not access language by either ear or eye, then how could they possibly have produced books, writings, and speeches? At the heart of this unfortunate debate was not whether a deafblind person could use language. Instead, it was about if language, intelligence, and competence could be perceived or expressed outside of popularly conceived norms. These norms and popular beliefs are largely centered on verbal speech and hearing that are unmarked by disability. Limited thinking about what language is and is not often excludes different ways of languaging such as touch, drawing, and gesture, and even the place of time itself in languaging.

The expansive linguistic potential of the human bodymind is best understood through a critical disability lens. The term bodymind, as we use it, marks the inseparable relationship between the body and mind. Although the body and mind are interconnected, different effects may emerge depending upon how people's disabilities interact with their other identities and social categories (Schalk 2018). Recognizing the bodymind is pivotal to understanding human linguistic potential because language is an embodied action or an expression of the interconnected relationship between mind and body (Bergen 2012). Bodyminds can be perceived as deficient because of gender (including nonconformity), race, fatness, ethnicity, or disability, among other identifiable traits both immutable and mutable (Baynton 2001). Linguistics reproduces and refracts structures of power by placing disabled ways of languaging on the margins through ignoring, minimizing, or seeking to correct how disabled people use languages. Meanwhile, many abled linguists stigmatize the language use of marginalized subjects by referring to their language as disordered. Disabled subjects from marginalized groups experience multiple intersections of language dismissal and stigmatization, as we will discuss later.

Linguists contribute to deficit perspectives of languages, and therefore, intrinsically to deficit perspectives of their users. We argue that the field requires broadening to account for how typically marginalized groups use language--a cripping of linguistics is necessary. This is the core argument of Charity-Hudley's essay, The Lung (in press). In that essay, Charity-Hudley examines how losing a portion of her lung to cancer forced her to examine the role of bodies in 
languaging and how different identities can change how people perceive bodies, especially disabled bodies.

Beyond providing lenses to help people study how disabled people use language, the theoretical framework of crip linguistics directly challenges disability stigmas surrounding language. The cripped linguist highlights the linguistic adaptions used by disabled people, including their relations and world-making, and illuminates structures of ableism that govern how we perceive language. As Hudley (2008) reminds us, activism is embedded in the field of linguistics. Linguists have an obligation to promote activism on behalf of the people who language.

Many linguists will wonder how Crip Linguistics goes beyond Critical Applied Linguistics (Pennycook, 2021). The answer comes from Pennycook's own Critical Applied Linguistics: A Critical Re-Introduction, which is a revision and update of the original 2001 book. In the chapter that focuses on the politics of difference, Pennycook writes, “...we will focus on forms of difference- typically along lines of class, race, gender, and sexuality- and why they matter for any critical applied linguistics project" (p. 84). Even within Critical Applied Linguistics, no frame of disability is used. Similarly, Piller (2021)'s recommendations on how to overcome linguistic injustice does not consider multimodality, nor how disability and disabled needs alter our concepts of language justice. Our goal is to bring disability into focus. There can be no Critical Applied Linguistics, nor linguistic justice, or any sort of linguistics, without analysis of disability. As Pennycook (2010) himself wrote, “...we cannot take language, the body, the environment, space as given entities with evident meanings...all these emerging orientations locate language as something done in a particular time and space." (p. 16.8). What is disability if not the interaction of language, the bodymind, and the environment as something done in a particular time and space?

\section{Crip Linguistics}

Crip is used in a variety of ways. For some, it is a slur. For us and in disability activism, and in activist oriented disability studies, crip is a verb (Sandahl 2003). To crip is to disrupt the stable, transform the familiar, subvert the order of things, unsettle entrenched beliefs, and to make anew. In action, cripping linguistics is to uncloak "mainstream representations or practices to reveal able-bodied assumptions and exclusionary effects" and "expose the arbitrary delineation between normal and defective and the negative social ramifications of attempts to homogenize humanity" (Sandahl: 37). Kusters and Hou (2020) point out that the overall pattern in linguistics is for linguists to treat language as separate from the people that produce language. While we have some linguists studying languages that are produced by disability ways of being and knowing in the world, a critical disability lens allows us to highlight problems with the status quo and possibilities for real transformation. 
Here we continue Kusters and Hou (2020)'s discussion of signed language research and linguistic ethnography, which introduces us to the novel ways of understanding linguistics through and by signed language researchers. We also extend Pennycook (2021)'s work on Critical Applied Linguistics. Our hope is that this article elevates the importance of talking about language as an embodied entity intertwined with people and shaped by researcher bias. Separating people from language is to dehumanize language users in pursuit of understanding language as a discrete entity. A critical disability lens exposes the ways linguists dehumanize language by using the rhetorics of "disorder" and "deficit", and that linguistics- including ethnography would be enriched by critical disability studies frameworks and theories. This enrichment is not limited to formal academic understandings of disability but also rooted in deaf and cripistemologies- deaf and disabled ways of being and knowing in the world (e.g. Hou \& Kusters 2020; Moriarity-Harrelson 2017).

This article is an attempt to create a mandate for change in linguistics and related fields such as specialized education. Crip linguistics means to critique language and language scholarship through the lens of disability, include disabled perspectives, elevate disabled scholars, center disabled voices in conversations about disabled languaging, dismantle the use of disorder and deficit rhetorics, and finally, welcome disabled languaging as a celebration of the infinite potential of the bodymind.

One example of why linguistics needs cripping is found in the general introduction to linguistics curriculum. While no hard data exists on the extent to which this is true, anecdotally, signed languages are not taught in introduction to linguistic courses as a languaging modality, but as a special or disordered kind of language that is usually regulated to a single chapter of a textbook if it is mentioned at all. For example, Anderson (2018)'s Essentials of Linguistics, a popularly taught open access linguistics textbook, has four chapters focused on sounds, and only a single sentence on signed languages in a summary, which inaccurately describes "hand signs" as the analogue for sounds (p. 33).

Part of this tendency to see non-speech languages as disordered is also reflected in BerkoGleason (and later Ratner)'s long revised book, The Development of Language (2017). Deaf people, in The Development of Language, are discussed in the context of "atypical" language acquisition (p. 5), in the context of primate language (more specifically that primate language studies had to fail for abled researchers to be interested in studying signed languages) (p. 12), in the context of deaf voices sounding "funny" (p. 54), and in the context of print literacy rates (p. 42). While some details are provided about the deaf community and signed language structures, phonology of language is defined as "all the important speech sounds it uses..." (p. 7). So signed languages are unnatural, disabled ways of languaging having no intrinsic merit for study, voices marked by accents are sources of humor and further marginalization, and low print literacy rates do not merit interrogation of the reasons for the low rates. 
Discussions of signed languages are often framed in deficit frameworks despite scholarship on Deaf Gain and signed language poetics (Bauman \& Murray 2014; Bauman, Nelson, \& Rose 2006). As little as there has been about signed languages in linguistics, other forms of disabled languaging have had even less discussion. The field of linguistics continues to place disabled forms of languaging on the margins while using ableist rhetoric to uphold racism, sexism, transmisia, and what crip theorist Robert McRuer (2006) describes as compulsory ablebodiedness and compulsory heteronormativity. Succinctly, linguistics needs cripping.

Crip linguistics emerges from historical and modern Deaf Studies examining how different cultures, primarily those in the U.S. and Europe, treat deaf children and adults. In deaf education, for example, racist and ableist beliefs about language combined with desires to justify racism, colonial policies, and ableist frameworks led to monolingual and monomodal educational approaches. Simply put, speech and trade (capitalism) became the primary learning mission over any kind of other learning. Those beliefs contributed to an epidemic of language deprivation for generations of deaf and disabled children through the school system.

Deaf Studies has a long tradition of discussing language attitudes and the relationship to personhood, humanity, and intelligence. A major thread is the relationship between language and the notion of evolutionary progress. The association of signed languages with beasts and lesser evolved humans means that signed languages and disabled ways of languaging became markers of abnormality and justifications for othering in creating "racist, ableist, and speciest hierarchies" (Clare 2017). Speech serves as a dominant marker of personhood, supported by centuries of religious thought and philosophy, reified by Darwinist theory, and reinforced by contemporary linguistics and linguists (Bauman 2004; Bauman 2007).

Deaf people, for example, are usually depicted in terms of poor behavior (Antia et al. 2011). Deaf children are additionally described as causing their parents stress by not being able to talk like hearing children (Quitner et al., 2010, Percy-Smith et al., 2018). As dis/crit scholars like Annamma, Boele, Moore, and Klinger (2013) explain, any child that exists outside of what is expected to be "normal" must swiftly and oppressively be corrected such that they can be normalized.

Structures surrounding language and ability are not static, as historians of sound, medicine, and technology demonstrate (Mondelli 2021; Virdi 2020; Nair 2020; Healey 2019). The attitudes that contributed to disabling deaf children in their schools by removing them from the accessible communication of the signed language classroom and their supportive peers, and placing them in hearing only classrooms, or in spoken and listening language only environments as described by Valente (2011) and Valente and Boldt (2016) are not limited solely to deaf children. Historically, language attitudes, including those manifested through linguistics and educational research, have 
severe consequences for disabled peoples' agency, personhood, belonging to different communities, and so much more. As disabled author Eli Clare (2017: 157) wrote, "in today's world, being seen as intellectually, cognitively, or developmentally disabled is dangerous because intelligence and verbal communication are entrenched markers of personhood." Clare claims the obvious: the weaponization of intelligence and language have cumulative effects on access to education, employment, housing, sexuality, respect, belonging, community, agency, and personhood. Ableist ideas about language are used with other structures of power to maintain capitalism, white supremacy, ableism, misogyny, homophobia, and transphobia (Alland 2018).

With language, we use crip time (how disabled people use time as a part of languaging), crip technoscience (or how people interact with technology), and linguistic care work (how disabled people work together to co-construct meaning) as frameworks to disrupt those various power structures and unsettle beliefs about what the appropriate ways to language are. Michele Friedner and Pamela Block (2017), through the frameworks of Deaf and Autistic Studies, suggest that disabled languaging should "challenge us to consider that which is non-linguistic as authoritative and meaningful." Crip linguistics resists compulsory abledness by celebrating disabled ways of languaging, the disabled knowledge that shapes language and communicative practices, and refusals to conform to "normal" language (speech). By heeding disabled people's relationship with language, languaging, and world-making, we note that disabled people are "effective agents of world-building and dismantling toward more socially just relations" (Hamraie \& Fritsch 2019). One major branch of this work appears in linguistic ethnography by signed language researchers. Kusters and Hou (22020) offer an expansive definition of linguistic ethnography to include signed language researchers who come from a variety of backgrounds but use a variety of ethnographic methodologies, named and unnamed, in their work.

Crip linguistics, as a theory, encourages linguistics to reintegrate languaging with all bodies. The framework can be used to recognize language as a critical site of agency and an important form of care work. Linguistic care work embraces interdependence between languagers as a practice of collective access in desire to work toward mutual understanding. Working together to ensure that all languages in conversation can make themselves understood, and be understood in kind is linguistic care work.

Language is central to our conceptualization of personhood. Language has long been used as a marker to separate humans from animals (Bickerton 2009). Perceptions of what is and what is not language, judgments on the quality of language, and decisions made on the basis of language (including accents and dialects) then possess tremendous power in determining one's humanity (Pennycook 2018). Language as a social institution plays a central role in determining a person's belonging in society. Disabled ways of languaging have been used to mark bodies as non-human and thus not deserving of equal treatment or a place in the world. The most popular application 
of animalizing disabled ways of languaging arose in the mid-to-late 20th century with human attempts to teach apes and chimpanzees how to sign (Pettito 2000). To this day, there exists a popular association of primates with signed languages to the point where it was a central plot line in Godzilla vs. Kong, a 2021 US based movie. Disabled languaging is seen in proximity to animal languaging. Like Berko-Gleason and Ratner (2017) write, interest in signed language research in humans only came about because of research on teaching primates how to sign.

\section{Modality Chauvinism aka What's our Motivation?}

As we've been pointing out, spoken language has long been tied to judgments of a person's capacity and intelligence, and by extension their humanity (Bauman 2004; Edwards 2012; Berger 2014; Clare 2017). Spoken language is also interpreted through a racialized lens to measure people's intelligence (Flores \& Rosa 2015; Rosa \& Flores 2017; Leonardo \& Broderick 2011), which uses rhetorics of disability, such as diminished capacities, to rationalize such framing. But as Flores and Rosa's combined research demonstrates, language itself is racialized and through those racialized lenses, the people who use racialized language are viewed as lesser. For example, Rosa (2019) focuses on how people with Spanish repertoires are viewed as less intelligent. As he writes, "Earlier that year, a self-identified White, monolingual Englishspeaking teacher explained to me that, among other signs of her stupidity, Dr. Baez's English language skills are 'horrible, and from what I hear, her Spanish isn't that good either."' (p. 126). The Dr. Baez mentioned in that passage had multiple degrees and was the principal of the bilingual school. Signed languages, as languages, are also racialized by who uses them, much in the same way that spoken languages are racialized. Hill (2012), for example, points out that white signers tend to have negative perceptions of black signers and their languaging.

Measures of intelligence were often coded measurements of a person's ability to pass as white (Henner \& Robinson 2021; Leonardo \& Broderick 2011). Language tests were used to determine mental fitness and by extension, permission to belong. For example, immigrants were subjected to mental fitness evaluations as determined through "discourse and conversation" between immigrant and the immigration officer. The immigration officer had no formal training in psychiatry. Dolmage argues that this discourse based interaction opened the doors for racialized measures of intelligence via language use (Dolmage 2011). Such interactions were certainly influenced by the officer's perceptions of the immigrant's perceived social categories. Ethnic exclusion would capitalize upon intelligence tests and mastery of language as justifications for exclusion. Thus to perform ability, one must also perform whiteness through both modality and language. Henner and Robinson (2021) described one aspect of performing ability as "performative hearingness" where deaf people are acknowledged for how much they are able to approximate hearing people in speech and mannerisms. In that case, hearigness becomes a property, or kind of indexicality that helps people align with the dominant power structures in a culture. As Leonardo and Broderick (2011) argue, intelligence and whiteness are also both property, and because language is a meditator of both smartness and whiteness, it is a significant 
site of property, power, and privilege, which then shapes the types of capital available from society. Language is a form of capital.

The crux of the issue is that many linguists consider speech to be the only viable and acceptable form of languaging. Few linguists will mention this overtly. And most linguists will point to gesture, or signed language, as evidence that language is not limited solely to the aural/oral modalities. That is because linguists are used to thinking of languages as spoken, and gesture and signed language exists only in special situations, or as abstracted and non concrete examples of how languages can be other than speech. Also, another problem is binary thinking. That is, only signed languages exist in opposition to spoken languages- that people use one or the other, rather than a combination of semiotic tools, that languaging can exist in spaces outside of conventional spoken and signed languages, e.g. using interaction and language games to co-construct meaning. Those binary structures suggest people either have language or do not have language and thus are languageless (see Moriarty Harrelson 2019 for a discussion of this). This binary thinking leads to erasure of the nondominant form. For example, at the time of this writing, the Linguistic Society of America (LSA), the pre-eminent professional organization of linguists in the United States, described linguistics as

In a nutshell: Linguistics is the scientific study of language. Linguists apply the scientific method to conduct formal studies of speech sounds, grammatical structures, and meaning across the world's 6,000+ languages (LSA 2021, p1).

If the LSA cannot identify that linguistics is the study of language, and not necessarily speech, then what does that say about linguists themselves and the status of non-spoken languaging in the science of language. While there are linguistic anthropologists who have contributed to understanding disability and language, revealing remarkable discoveries about cognition and human nature, this information has been siloed from the work of many theoretical and applied linguists.

The artificial limitation of linguistics to speech is an automatic extension of the cultural belief that the only valid languaging is speech. This belief shows up in many linguistics based media. For example, the below meme (Figure 1) 


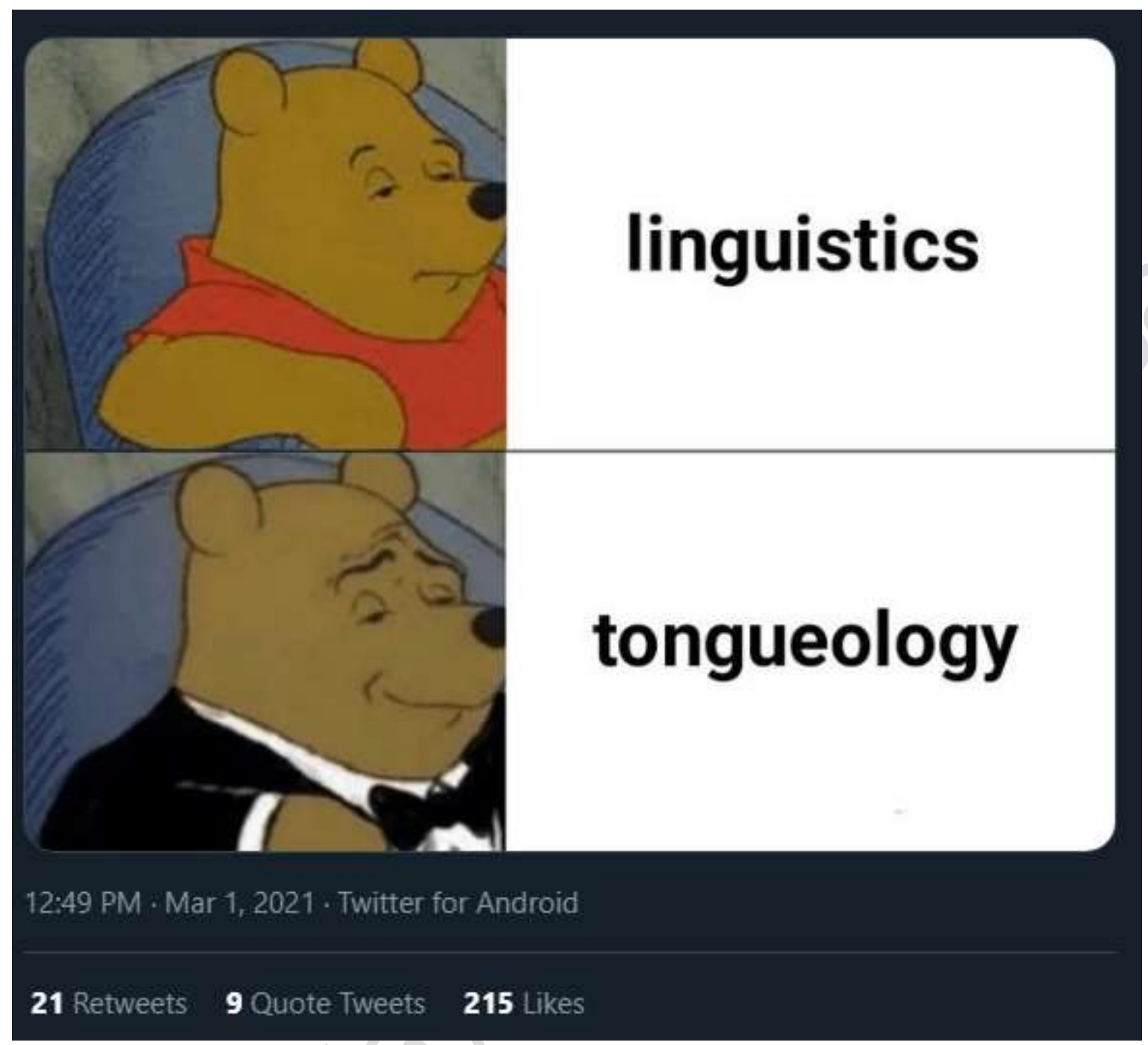

The meme is an example of the Tuxedo Pooh structure. Tuxedo Pooh can progress through multiple layers of sophistication, where the associated sophistication is matched with an equally sophisticated Pooh. The t-shirt Pooh represents the less sophisticated idea, and the tuxedo represents the more sophisticated idea. The idea associated with the Tuxedo Pooh may not appear more sophisticated on the surface (e.g. the sophistication of linguistics is not tongueology), but can be abstracted in ways where the surface humor provides layered meaning a-la semiotics (Merrell 2016). For example, if one believes that languages can only come from the tongue, then linguistics would be the study of tongues (e.g. mother tongues, or here, tongueology).

We have previously argued that part of the reason that scholars tend to avoid talking about signed languages and gestures is that the communities that use them as a primary form of languaging are disabled (see Henner \& Robinson 2021) or that individuals are deficient, removing them from their environments and interlocutors (Goodwin 2004). The pathologization 
of signed languages emerged in the 18th century with the installation of Dr. Jean Marc Itard at the Institut National de Jeunes Sourds de Paris. Itard classified deaf children on the basis of language use, marking those who signed as more deficient than those who could partially hear and emulate speech (Lane 1976). This disabling effect is also observed in how people separate language users from their semiotic matrixes: their environments, their interlocutors, and the linguistic resources available (Goodwin 2004). The social and relational models (e.g. Kusters 2015, Goodwin, 1995 Goodwin 2004) suggest instead that signed languages and other forms of languaging across modalities and the semiotic matrix are influenced by our environments and material conditions as well as social attitudes and relationships. This cannot be decontextualized from local understandings of disability and debility (Livingston 2006; Grech \& Solidatic 2015). So language is either modeled as deficient through pathologized views of the body or negative racialized views of the body (Flores \& Rosa, Rosa \& Flores) or viewed as a relational act, influenced by social attitudes about language.

The relationship between disability and language also contributes to the institutionalization of deaf and disabled people, markedly impacting non-white deaf and disabled people.

Institutionalization also locked away disabled people in institutes and prisons, often for life, as was the case for Junius Wilson, a black deaf man (Burch \& Joyner 2007). Given his prior education at a segregated school for the deaf, it is likely that Wilson used a form of Black ASL (see Hill 2017 for a description). When Wilson was brought in for questioning and criminal proceedings, he was found incompetent to stand trial because he was perceived as a languageless person. One of his interviewers was the jailer Carl Cook who claimed he knew sign language; the problem was that he did not know Black ASL or even that such a dialect existed. He then read Wilson's black and deaf body as languageless, or in his words, incapable of "coherent" or "intelligent" answers. This determination led to a series of events that included sterilization and seven decades in an institution; his imprisonment continued even after social workers discerned he was able to communicate in Black ASL.

Linguists generally understand that languaging is used in forms of oppression. As Blommeart (2005) wrote in his introductory textbook on Critical Discourse, "...differences in the use of language are quickly and quite systematically translated into inequalities between speakers" (p. 70). In parsing this quote, most linguists are able to recall specific studies or vignettes which explore how language differences create marginalization. Pillar (2020), for example, argues that in most places language discrimination is acceptable. Certainly, language is used to oppress across gender and sex (Zimman, 2019). Zimman (2019), for example, explains how pronouns are used to force notions of correct sexuality and gender representation on trans bodies. An explicitly misgendered person is informed that they are not performing their undesired gender correctly; it is an attempt to linguistically repair a perceived physical error (e.g. you are not an adult human female). Language is used also to enforce racial distinctions. Rickford and King (2016), for example, detailed how African American English (AAE) creates judicial inequalities wherein the 
use of AAE and dialectical variations of AAE causes white people to discount the lived testimony of Black witnesses. Language can also be used to racialize a group of speakers. Rosa (2019) detailed how a community of Latinx teenagers in the United States navigated English, Spanish, and how brownness and foreignness is attributed to speakers of Spanish regardless of where they live and their upbringing. Language also marks social class (Block 2015). Class, for example, situates forms of languaging, such as if bilingualism is prized or a method for racialization and sorting into specialized education classrooms (Cioe-Pena, 2020).

The examples of sex/gender, race, and class are not the only types of ways that language is used to oppress, although they are among the larger categories of discission, although Block (2015) argues that class is not considered a factor in enough applied linguistics analyses. As mentioned before, disability is a prominent category by which language is used to oppress. Language use both disables, and represents disability. This is partially evident in how people reflect language use as disordered, such as Specific Language Impairment (SLI) or Developmental Language Disorder (Bishop 1992). Disabling language also shows up in comments such as "learning disabilities are language disorders" (Sun \& Wallace 2014). Disabling language exists in ways outside of the school system as well. For example, the Hart and Risley posited a 30 Million Word Gap which was presented as evidence that racialized and poorer families do not expose their children to language equivalent in "quality" or quantity to non-racialized and wealthier families (Hart \& Risley, 1995; 2003). Regarding the 30 million word gap, Figueroa (M. Figueroa, Personal Communication, 2021) points out that were it real, it would be a form of extreme language deprivation. Language deprivation is a form of disabling abuse that is normally limited to children who are born deaf or hard of hearing (Hall, Levin, \& Anderson 2017). Yet with the 30 Million Word Gap, people seem to be working to expand the definition of language deprivation and its disabling effects to include racialized people and people in poverty.

\section{Coming to Claim Crip Linguistics}

The clear relationship between language, linguistics, and disability necessitated the introduction of a disabled lens through which languaging can be analyzed. To do this, we will claim to crip linguistics and propose a framework of Crip Linguistics. Crip Linguistics is not novel nor new. Disability has long been a part of linguistic analysis. But a Crip Linguistics intervenes in mainstream linguistics discussions to destigmatize, yet center, disability in conversation.

As for disabled ways of languaging, we seek not only extraordinary examples of the normative like signed languages but also the more quotidian and local forms of disability like stuttering, crippled speech, and as Friedner and Block (2017) highlight, "attend[ing] to other forms of communication and meaning making that are not linguistic." (p. 290). We heed Friedner and Block's caution that foregrounding signed languages need not result in not engaging with other ranges of communicative repertoires or the more daily forms of disabled languaging. Friedner and Block posited questions about disability frameworks of languaging at the intersections of 
Deaf and Autism Studies, encouraging us to expand definitions and understandings of human language as well as how our discourses surrounding disabled languaging contributes to hierarchies of disability e.g. the speaking deaf person (performative hearingness, Henner \& Robinson, 2021) and the verbose autistic person (Friedner \& Block 2017). How might a disability framework of language teach us about ways of dismantling toward more just relations? That is, disabled languaging is not just about the individual but also their linguistic ecologies and semiotic matrixes. One illumination of this is Moriarty and Kusters (2021) who wrote about the morality infused translingual practices among deaf people who come together using different signed languages and possessing different semiotic repertoires.

To promote Crip Linguistics, we offer some grounding statements that will guide this overview. The statements will become sub-sections and will be expanded upon. They are:

1. A Crip Linguistics is necessary for analyzing human languaging, lest we reproduce inequities

2. A Crip linguistics recognizes that languaging is multi-modal

3. A Crip linguistics embraces disabled ways of being in producing language: sensory orientations, interdependence, mutual-aid and world-building, carework, and the ways that time interacts with the bodymind and language.

\section{A Crip Linguistics is necessary for analyzing human languaging}

\subsection{An Introduction and Some Caveats}

A crip linguistics holds three essential truths: a) language is not inherently disordered although impairments may exist and b) social perceptions on disability disorders language use, and c) disability in languaging cannot be separated from normative expectations of language use. Crip linguistics is a natural extension of the idea that all language variation is acceptable (e.g. Labov, 1972). We expect that most readers will take easily to the second and third stipulation of crip linguistics. The first may be a bit more difficult to digest because the idea that language as disordered is fundamental to many fields (e.g. specialized education). One thing we want to stress is that no theory is perfect, including ours. For example, what of deaf children who are deprived of language either through malice, or through ignorance (see Hall, Hall, \& Caselli 2020)? Is their resulting language not disordered? Here is where threading the needle on this very real question could have consequences. Their language was impaired by their material conditions and environmental factors, but their language is not disordered because they are deaf children that would naturally gravitate to signed language and multimodal avenues of communication. Language deprivation results in language that then must be accommodated to encounter the ableist structures that generated such conditions in the first place.

If people misunderstand our argument that the language manifested from language deprivation or other inequities generated by material conditions is not inherently disordered, then there is a non- 
zero chance that schools and early intervention specialists attempting to save money would use our theories as justifications for not providing support. We exist in a world where identification of disabilities for educational support services is fraught with bias, and racial and gender based discrimination (see Fisher, Fisher, \& Railey 2020 for examples). Yet in the States, identification is necessary to get the support that many disabled children need to manage the ableist, racist, and sexist institution that is the American school system (Annamma \& Morrison 2018).

Also, there is a possibility that people opposed to non-spoken modalities would use our theories as justifications for enforcing their monomodal frameworks. This has happened before when advocates of fluent signed language environments for deaf children found that monomodal opponents were using those arguments to claim that since hearing parents of deaf children could never be fluent in signed languages, they should just use monomodal approaches to education (see Geers et al., 2019)!

Because of disabling legal and cultural systems, disabled languagers often exist in the borderlands between disordered and non-disordered. The dichotomy between disordered and non-disordered is rendered in Moriarty-Harrelson (2019). The deaf Cambodians described in her research are classically language - disordered (in that no language is inherently disordered) in that they are deprived of language by their environment. However; via competence they create systems of languaging that "expand as they enter new spaces, resulting in the flexible accumulation of languaging practices and modalities" (p.1). Moriarty-Harrelson concludes her point by reminding us that we cannot dismiss how the deaf Cambodians language just because they do not use a formally recognized Cambodian Signed Language. The core of our argument is don't hate the player, hate the game.

We also explicitly reject those people who would use our arguments to confer harm upon disabled children via language deprivation. Crip Linguistics is fundamentally a resistance against monomodal, spoken language only policies, and the belief that there is one right way to language. It also urges us to assume that all people are competent co-participants in constructing meaning. As Goodwin (1995) urged with Rob, an aphasic man, "deal with his talk and gesture as an effort to say something meaningful, rather than the random movements of" a disabled man. It should not be used to argue that deaf people should not have access to natural signed languages, for example because they can build a communicative repertoire using systems, cues, and incomplete access to spoken language. Part of this is because non deaf children automatically have access to natural languages whereas for most deaf children (approximately 95\%) this choice must be made, and the reasons for these choices are often rooted in ableist, anti-signed language rhetoric (Scott \& Henner 2020). Crip linguistics frames language as a form of care work where we work collectively to provide access and co-construct meaning. In the words of Sins Invalid, a disability justice performance group, "bring flexibility and creative nuance... to be in community 
with each other." (Berne, 2018). Therefore, it is a form of care work for us to accommodate disabled bodyminds and their natural ways of languaging.

We also reject the use of Crip Linguistics to discriminate against or to diminish the desires of people who want their language to be identified as disordered. Because our world is constructed as such that sometimes pathologization of language as disordered is the only way that one can receive the accommodations and legal protections one requires as a non-normative language user. This stance does present an odd contradiction to our point that language cannot be disordered. Yet, like with language deprivation, recognizing the complexities between environmental disordering of language, justifying that all languaging is valid, and self perception of languaging is valid! On this point, we recognize that crip linguistics is not universal across all contexts. As Robert McRuer (2010, 171) explains, disabled people experience uneven biopolitical incorporation. What that means is that disabled people and by extension, disabled ways of languaging, are not treated the same socially or politically across the globe. Disability, as a category, is fluid, dependent upon context and material conditions (Schalk 2013; Livingston 2006; Grech \& Soldatic 2015). However, a critical disability lens on language offers important insights on how we judge capacity, humanity, and belonging (or the worthiness of belonging) and how those logics support the logics of exclusion, disempowerment, and violence. To crip linguistics is to examine practices, attitudes, and rhetorics through a critical disability lens to reveal ableist assumptions and its exclusionary effects.

There are certainly cases where application of crip linguistics is fundamentally flawed. We also go back to our assertion that no theory is perfect and cannot be pertinent in every single case. People are intricate beings with desires and thoughts that vary from minute to minute, and these thoughts often contradict each other! As Whitman writes in Songs of Myself, 51, "Do I contradict myself? Very well then I contradict myself, (I am large, I contain multitudes.)". Understanding how these contradictions can exist but also not invalidate our claims requires that we use both disability studies and trans studies. The former is evidenced in both Liz Crow (1996)'s work and also Margaret Price (2015)'s work on pain disorders. The latter in work from trans theorists such as Florence Ashley (2020). We will not spend a lot of time on them here. Suffice to say, the desire to have release from pain does not negate disability theories; the desire to transform one's body to align with gender identity does not negate queer theories. Similarly, the desire to work on ones' languaging to make it feel less disordered does not negate Crip Linguistics. In writing, the monomodal format often requires essentialism (Bucholtz 2003). In other forms of languaging, the multimodal format allows for linguistic boggarts, faes, and quislings, wherein multiple truths can exist in the same sentence in constantly shifting meanings depending on the suprasegmental facial and bodily gestures. As the 10th Doctor (Series 3, Episode 10) would say, "This is wibbly-wobbly timey-wimey stuff"! The nature of Crip Linguistics defies essentialism. 
With the caveats in place, we will explain both the stipulations of crip linguistics, that language cannot be disordered, and that the environment disorders language.

\subsection{Language use cannot be disordered}

The idea that language use cannot be disordered is admittedly an unusual one in their world of speech and language pathologists, specialized education teachers, among others who have worked their entire lives on the question of how to un-disorder language. For us to accept that some kinds of language are disordered, then we need to accept that there are ways of languaging that are wrong. Disordered language has multiple definitions depending on the field. They can be defined via expressive language (difficulties communicating in ways that others can understand), receptive language (difficulties understanding other peoples' communication), or even developmental (difficulty acquiring language) (Paul, Norbury, \& Gosse 2018). We accept that deciding that a kind of languaging is wrong has many different perspectives. First, people do feel that languaging is wrong when the languager uses dialectical variations that vary from privileged groups decide is the best possible way to language (e.g. raciolinguistics) (e.g. Cioe-Pena, 2020).

Second, people feel that languaging is wrong when a child languages in different ways to the people in the house that they live in (e.g. deaf children in hearing families) (Hall, Eigsti, Bortfield, Lillo-Martin, 2016).

\subsection{Racism in Language Disorders}

Yet, expressive and receptive language disorders are often wrapped up in racist assumptions about what the appropriate way to express and receive language is. As many researchers and community activists point out, Black children are often identified as having expressive and receptive language disorders related to the fact that racist systems are integrated into the educational experience (e.g. Baker-Bell 2019). Yet the political fracas of the late 20th century Oakland, California Ebonics controversy demonstrated that people are willing to discard evidence based research when the evidence does not match their agenda (Vaugn-Cooke 1999). At the time, the Oakland school board had passed a resolution allowing the use of ebonics as a language of instruction and assessment. The school board later discarded the resolution and its possibly revolutionary changes in pedagogy. Understanding the Ebonics controversy is critical because children whose home language may differ from the school language are often assumed to be language disordered (Yamasaki \& Luk 2018; Cioe-Pena 2020). As Yamasaki and Luk point out, multilingual and multimodal children are often assessed using language assessments which do not consider the myriad ways that they language. Depressed scores on these assessments, coupled with racist and ableist biases of the assessors means that multilingual and multimodal children are often considered language disordered.

\subsection{Accentism and Language Disorders}

As mentioned before, our definition of "disordered" is broad and refers to any languaging that is seen as in need of correction or fixing through various therapies. The association of disordered 
language with racism means that accents need to be discussed via the Crip Linguistics lens. Therefore, if the goal is accent reduction, then this is seen as disordering language because the accent does not sound appropriate for "non-disordered" listeners. Ramjattan (2020) interviewed 7 international Engineering teaching assistants in Ontario, Canada to detail their experiences being perceived as disordered speakers because of their accents. This population was chosen because, as Ramjattan pointed out, accented international teaching assistants are considered to be deficient. Deficient, of course, can be interpreted as disabled. While Ramjattan analyzes the data using a prism of racism, the language used to describe the accents and interpretation of the accents by "native" speakers requires a disability analysis. And that includes signed language research. DeafBlind and DeafDisabled people who use signed languages may be subjected to accentism on basis of how their language is impacted by bodymind differences, e.g. those with cerebral palsy and those who use pro/tactile sign languages (Burke 2018; Hayes 2021, personal communication). Accented people are deviants, deficient, and require therapy and adjusting to fit into the expected norms of "native" (abled) speakers. Ramjattan's participants speak about being laughed at (abled gaze), about people and their students and peers refusing to understand what they're saying (refusing accommodations).

\subsection{Gender in Language Disorders}

Perceptions of disordered language can also be attributed to rigidly enforced gender roles. In the U.S. at least, language from people who are perceived to be femmes is often policed by both masculine and feminine people. This often manifests in the form of negative feedback from audience members about structures that are perceived as feminine such as tag questions, or quotative like, or vocal fry. Like Figueroa and Gillion (2018) explain in the Vocal Fries podcast, once a structure is identified as femme, it doesn't matter that people who are masc also use it, the structure is considered deficient. The example they use in their $9 / 10 / 2018$ podcast is Johnny Cash, a United States country singer from the mid to late 20th century. Gillion also points out that what is femme identifying in some languages (e.g. U.S. English) is part of the phonological productivity in other languages. The example used is a Mexican language, Jalapa Mazatec, where the creaky voice produces a minimal pair. Some readers may be confused about why we are including this in the concept of disordered language. We assume that if language is interpreted as being wrongly produced, then it is in the mind of the perceiver fundamentally disordered and in need of fixing. Indeed, fixing femme identifying language is a product in the U.S. where individuals can pay money to train out of using these language elements. Accordingly, femme identifying languaging is also a good example of how the environment disorders language because feminist spaces do not disorder femme identifying language.

\subsection{Sexuality and Language Disorders}

In 2009, van Borsel et al. published a study that indicated that gay men were more likely to be identified as lisping. While van Borsel et al. explain that lisping, or "a speech pattern in which alveolar consonants are pronounced with the tongue either on or between the front teeth" (p. 100) 
is not necessarily seen as disordered speech in children, it is recognized as one in adults. Notably, van Borsel et al. argued that lisping was likely acquired in childhood as a way to identify with femininity. The adults who lisped; however, did not see their lisping as a deficiency, but rather, a marker of identification with a community. Although the population in van Borsel et al. found their lisp to be a positive identification with a marginalized group of people, Holmes (2019) seems to argue that in the hetero gaze, that while the lisp is used to identify with femininity, the user attracts fetishization and infantialization which means that people outside marginalized groups may use this positive identification in negative ways. The emphasis on infantilization mirrors van Borstel et al.'s assertion that lisping is seen as fine for children, but not much for adults. More recently, Calder (2020) points out that how we perceive sounds (or signing) cannot be entirely separated from how we perceive the person. More specifically, if we assume someone to be feminine, then we are more likely to assume that they are lisping too. That is, disability, infantilization, and queer femininity are intractibly linked.

\subsection{Crip Speech}

The focus on speech as the modality means an unnecessary focus on the aesthetics of so-called proper speech. This of course is a driver of racism and sexism in languaging, as discussed previously. A prenatural focus on aesthetics also allows for business models for those who sell products that masculine-up, or reduce accents in speech with the goal of making pleasing to the ear. Pleasing to the ear is intertwined with layers of gendered expectations- beautiful voices, sexually attractive voices, masculine and feminine voices. Pleasing to the ear also is racialized, with sexy accents often regulated to specific European accents (e.g. Irish) or white colonizers in non-European countries (e.g. Australian). Pleasing to the ear is often described as "natural" or imagined as what should be natural. For example, people perceived as women are expected to sound a particular way; to have masculine or rough speech (e.g. creaky voice) would be described as unnatural, ergo, abnormal. Notions of naturalness extend to the sound of what one expects human speech to sound like.

What happens when speech sounds different because of disability? Stuttering, lisping, mumbling, stammering, slurring are all markers of difference. Those markers signify not only disability but are also interpreted as lack of intelligence, capacity, and agency. Those markers are subsequently used as rationale for exclusion. As QuietBob, a participant in Marshall (2014) who uses alaryngeal technology to speak says, his speech isn't disabled but people who have normative hearing interpret it as disabled. Assumptions that a speaker is competent only if "fully endowed with abilities" is disabling and more so in a society where "the cognitive life of the individual" is its primary focus. In a society that values intelligence and ties that with linguistic competence, assumptions about a speaker's competence takes on significance (Goodwin 2004).

Deaf people understood that people's intelligence and overall competence were judged on the basis of their capacity for speech. And one level of this judgment was intelligence, which was 
then tied to being viewed as worthy of participation in society as citizens (Robinson 2010). Much of deaf people's linguistic advocacy surrounding crip speech and signed languages has centered on the fact that modality is not a signifier of intelligence, that signed languages are equally capable as spoken languages in communicating complex and abstract concepts, that deafaccented speech is simply a function of not hearing the spoken language as produced, that deaf mouthing is a product of print literacy. Some of those arguments have admittedly been rooted in ableist rhetoric in efforts to distance themselves from other disabled people (Titchosky 2001; Robinson 2010). However, we recognize that deaf people who speak can and do use speech as a measure of proximity to hearingness and thus ability (see Ladd 2003; Henner \& Robinson 2021).

Yet Marshall (2014) complains that too much focus is given on the deaf experiences of crippled speech, and not non-deaf experiences being speech divergent. The underlying assumption of Marshall's point is that deaf people are expected to have crippled speech. Hearing people are not and when disability cripples hearing speech, then that is extra devastating. Indeed, Holmes (2019) posits that the goal of dysfluency studies is to remind disability studies of its tendency to overlook the role of hearing and speaking in marginalizing specific disabled groups, even within disability studies. As deaf scholars we are not in a position to argue against that perspective. Nevertheless, no doubt exists about the proximity deaf people exist with normative hearing and speech expectations, especially given the goal of deaf education is often speech at the expense of everything else (Baynton 1996).

The pathologization of signed languages subordinated divergent languages and speech, establishing what McRuer (2006) describes as a "compulsory ablebodiedness." Compulsory abledness established norms where deaf children could and should learn to speak, and that through sufficient training, defects of the vocal chords, of speech, and of non-verbality, would be erased. In creating this compulsory abledness, vis a vis fluent use of spoken languages without accent, created expectations for the production of speech and language. And those who decided to use language outside of those expectations were deemed unruly bodyminds who did not want or could not be "restored" to society (Edwards 2012). What this did was generate stigma. By associating stigma with disability (different ways of using language), medicine and education intersected to create stigmatized forms of languaging and fueled phobias about disability.

To sum, the emphasis on speech and speaking as the sole language modality perpetuates not only ableism, but sexism, racism, cisheteronormative ideologies. To move past these ideologies, an emphasis on linguistic multi-modality is not only needed, but essential.

\section{A Crip Linguistics Recognizes that Languaging is Multi-Modal}

Friedner and Block (2017) once asked, "how might current research on multimodality and the use of expansive communicative repertoires in language and communicatie create new pathways 
for understanding deaf and autistic peoples' language and communication practices?" We extend this question to more broadly ask this of linguistics: "How does understanding current research on disabled languaging and critical disability studies help us better understand language at large and its relationship to structural exclusions?"

That language is multi-modal is not a new idea in linguistics. Bolinger, in 1946, wrote

For some reason, the very insistence upon language as a spoken phenomenon, i.e., as behavior, has been accompanied by a close concentration upon a limited number of behavior patterns, the latter suggestively reminiscent, in their selection for ease of recordability of the 'written forms' from which we were supposed to have been emancipated. It is only by a return once more to the whole of communicative-behaviors with energies of linguists more evenly distributed, that we shall avoid the over-growth and premature refinement of one or two component parts. (p. 92).

Here, Bolinger suggests the focus on language as unimodal, or speech alone, was done because it is convenient. Most linguists use spoken language. Many linguists use languages that use spoken phonemes as the basis for coding into written modalities. Bolinger correctly recognized that this limited linguistic analysis to what can be recorded and analyzed via "written forms".

The challenge of reliance of written forms and written modalities for linguistic analysis means that 1) languages without easily accessible or standardized written forms tend to be left out of linguistic analysis (e.g. signed languages), and 2) the bulk of language analysis is done on languages and language materials from dominant languages and cultures (see Bender et al. 2020 for an explanation). An example of point one can be found in Thompson, Roberts, and Lupyan (2020)'s description of cultural influences on word meanings. Thompson et al. sought to find to what extent word meanings in spoken languages are aligned. As they explain it, words that reflect common, everyday experiences outside of the boundaries of geography and culture (e.g. eat) should be aligned, or used similarly, in similar contexts. In the fields of deaf education or signed language interpreting, we would claim that semantically aligned terms would have oneto-one mapping. However, the data they used came from the NorthEuraLex dataset (Delbert et al., 2019) which has no signed languages contained in it. That means the Thompson et al. claim that they have data from 41 languages is not entirely accurate. They have data from 41 spoken languages, and accordingly, their conclusions about semantic alignment says nothing about language specifically. Rather their conclusions can only be applied to spoken language.

The limitations of NorthEuraLex is due to the lack of a standardized printed form for many signed languages (Grushkin 2017). No printed form, means no inclusion in the database, means no analysis that can be generalized to languages per se, and the field remains focused on spoken languages alone because spoken languages via orthographies are easier to analyze. 
That languages need written forms to be analyzed is a recursive problem. To analyze languages abstracted from the speaker, they need to be written. If a language is not written, it cannot be abstracted from the speaker. Historically, the response to this recursive problem has been to develop written forms for these languages (Grushkin 2017). In the case of deaf children and signed languages, this requires that schools who teach those children pick and use a written form. But that will not happen because there are many competing systems, and the usual complaints about teaching a written language that is not the printed form of the spoken language will arise. But also, it encourages the belief that the only way for a language to be valid, is for it to have a written language.

In this section we will briefly examine three aspects of multi-modal language that linguists need to consider when analyzing language. Although linguistic ethnographers and theorists like Pennycook have included expansive modes of languaging in their work, we believe that theoretical linguistics continues to ignore the semiotic repertoire (Kusters et al. 2017) in its stubborn adherence to modality chauvinism. Here, we outline a few aspects of languaging that theoretical linguists should include in their work. They are: a) visual language (e.g. signed languages, gestures), b) graphemic languages (e.g. sequential art, iconicity, and alternative and augmentative communication (AAC)), and c) tactile languages. We recognize more modalities exist (e.g. written). Our exclusion of them is not meant to marginalize. We have selected these three as possible areas of focus, but if more can be done then they should be done.

\subsection{Visual Language}

Of the three aspects of multi-modality discussed in this article, the visual language modality has had the most focus by linguists. Our discussion therefore is not on what parts of visual language can be analyzed by linguists, but rather, to what extent should focus on visual language be embedded in all linguistic analyses and in the linguistics teaching curriculum. In visual language, we do not distinguish signed languages and gestures, except to point out that previous essentialism on what is gesture and what is signed language was necessary to promote the idea that signed languages are true languages. Even today, researchers conflate gesture and signed languages to make the claim that signed languages are inferior or not real languages compared to speech (see Crowe, Marschark, Dammeyer, \& Lehane 2017 for examples). Our perspective is very clear. At no point in the curriculum should spoken language compositionality be mentioned without visual language compositionality. Succinctly, no mention of PRAAT without ELAN.

More to the point, all human languaging is multimodal (Perniss 2018). Any teaching or analysis of language which does not consider multimodality therefore does not compose language itself, but rather a specific modality in languaging. To be clear, if an analysis of a language only considers the spoken modality, then it is not an analysis of language, it is an analysis of speech. 
Even signed language researchers are not immune to challenges in discussing how disabled people use language. As Hou and Kousters (2020) point out, signed language researchers tend to classify visual languages among gesture-homesign-communal-village-national-urban groupings. These groupings can divide users among disability and racial lines. Whose language is gesture? Whose is homesign? Whose is urban? These categories need to be analyzed within a crip linguistic framework.

\subsection{Graphemic Language}

Graphemic languages as used here includes a wide range of pictorial based communication, such as icons, signs, drawings, computer graphics, memes, emojis, and sequential art. Semiotic analysis is not unknown among linguists (e.g. Merrell 2016). And recent internet linguists such as McCulloch (2020) have brought analysis of graphemic language to general populations. However, linguistic analysis of how people use graphemic languages as a primary form of languaging seems limited, except in domains of specialized education (e.g. Soto \& Olmstead 1993). Works such as von Tetzchner (2015) demonstrate the semiotic potential of AAC. And people who follow AAC users on social media, such as @semispeaking, can witness the immense intertextual knowledge required amongst AAC users for using and developing new iconicity. However, even von Tetzchner frames AAC users as being deficient; the users have "failed" to develop speech.

There has been some major work on sequential art as being linguistic by Cohn (e.g. Cohn, 2019). Cohn has worked to show that sequential art can be broken down into constituent parts, much like spoken, signed, and written language. For example, a series of sequential images can be clustered into an Arc. The Arc is broken into Establisher, Initial, Prolongation, Peak, and Release sections. Each section can add complexity via clauses. Cohn's theories have repeatedly been supported by analyses of brain waves (Event Related Potential; ERP) which evidence that the brain sees and processes sequential art linguistically. The sequential art as linguistic is further supported by the research which indicates that seeing sequential art as linguistic requires exposure and training (Cohn, 2019). Yet, once a skill is seen as normative, people apply normative expectations to having the skill and children who do not conform to these normative expectations are seen as deviant. Manfredi et al. (2020) studied the visual narrative processing of autistic children and compared them to abled children. They found differences in how the autistic children perceived the visual narratives. This, according to Manfredi et al. was a deficit. In explaining the results, Manfredi et al. pointed to the lower IQs of the autistic children as one explanation for the differences in perceiving narratives, thus contributing to the idea of language, intelligence, and disability being linked. Here we wish to remind readers that differences should not be seen as deficits!

Another avenue for linguistic analysis of graphemic language is Augmentative and Alternative Communication (AAC). AAC is used by people who do not speak and do not sign, for a variety 
of reasons. Many kinds of AAC exist (see Ganz 2015). The most recognizable forms are icons that are used via technology (e.g. an iPad) or a communication board. AAC users point to or press the icons. Some complex AAC device will associate a sentence with an icon such that the AAC user can press an icon and the device will speak or write the associated sentence. Although ableist perceptions of AAC as inferior to speech an even signed languages mean that many young, disabled children do not have access to a workable AAC system for years (see Moorcraft, Scarinci, \& Meyer, 2020 for a discussion), adult AAC users show the same love for their AAC as many marginalized users of a language. TuttleTurtle, for example, points out that AAC is a necessary part of their gender presentation, evidencing that as a language, AAC has the same indexicality of disability, gender, race, and sexuality, among others as other kinds of languaging.

\subsection{Tactile Language}

DeafBlind people have recently introduced the notion of ProTacticle, a philosophy of communication that embraces the use of touch as a sensory pathway to language and cognition (Edwards 2018; Bradbury, et al. 2019; Clark 2020). During conversation, DeafBlind people use the senses of touch, movement, heaviness and lightness to receive language from interlocutors. The interlocutors lend their hands, arms, bodies to the DeafBlind signer, allowing their bodies to be manipulated to co-construct meaning. Touch can be used to communicate environmental information, not only what is uttered, but to also give the DeafBlind person a sense of space, surroundings, and audience responses. In a show of the expansive potentiality of crip language, John Lee Clark prepared a presentation where he co-created content in clusters with attendees. Each group experienced and understood the message in different ways, depending on shared knowledge and with the expectation to respond in collaborative ways. Clark rejects the premise that it is possible for audience members to get the same message. Instead, the audience coconstruct the speech, inserting their perceptions and worked toward mutual understanding. The attendees did not experience the speech in the same order, they received the speech in different parts at different times with meanings that shifted with each group.

\section{Crip Ways of Being in Language}

Critical disability studies offers frameworks for thinking about, talking about, theorizing, and applying linguistics to disabled languagers. Linguistic ethnographers who work with deaf and disabled people have shown us how disabled people use language (e.g. Hou \& Kousters 2020; Moriarty 2019). Yet as we've pointed out, this work has not bridged to theoretical linguistics, or even applied linguistics (e.g. Pennycook, 2021). Here,we make connections to critical disability theories by examining languaging through a critical disability lens. In critical disability studies, theorists are encouraged to ask questions like how is normativity defied? How are white, ableist, and Eurocentric ways of thinking about language exposed?. Disability Studies scholars have theorized Crip Time, Interdependence, and Crip Technoscience, which help theorists analyze interdependence, relationality, mutual-aid care work, adaption, and innovation thematically. 
Those frameworks, through a critical disability lens, shifts our conversations about time, space, and the body in relation to language.

\section{Adaption of Critical Disability Studies to Theoretical and Applied Linguistics (Critical Disability Applied Linguistics: CRIP Linguistics)}

In disability studies, there are conversations about how disability shapes our relationship with time. As Disability Studies scholar Ellen Samuels (2017) outlines in "Six Ways of Looking at Crip Time," disability stretches, bends, contracts, and explodes time. Crip Linguistics exists within Crip Time. We recognize time as a factor that generates deficit perspectives about language and contributes to the disordering of language through attitudes and expectations. What happens when we have "crip departures" from normative time?

Abled people expect language acquisition to take place on a very specific timeline, with limited investment from themselves. Children are expected to achieve linguistic benchmarks by certain ages (e.g. critical periods), and often these benchmarks are facilitated by co-development of physical traits among similar checkpoints. For example, Walle and Campos (2014) argue that language development is related to the acquisition of walking. Does that mean children who do not walk do not acquire language or that their language is in deficit? They do not study nonwalking children. However, children who use mobility augmentation and technologies such as wheelchairs can, and do learn language.

Any failure to meet benchmarks on time reinforces deficit views of the language produced by disabled children. The normal timeline is determined by ideals and averages as imagined by academics, medical professionals, and educators. This does not take into account how different bodyminds take time to process and acquire language. Then when those children fail to meet those temporal linguistic benchmarks, they are labeled with disordered language. For example, Hoff, Tulloch, \& Core (2021) seem to imply that children who are not English dominant bilinguals by 5 years of age may be intellectually disabled. Those timelines create and reinforce deficit ideas about children's intelligence and agency. Crip linguistics urges us to think about the fluidity of time and the capacity of the bodymind to develop language, achieve understanding and communication.

Abled people expect communication to be quick, efficient, and spoken. As Samuels and Freeman (2021) point out, "what is nearly always true, however, is that using a different form of technology for access reasons means everything takes longer. And this is true not just for users of complex technologies like screen readers: differences such as having only limited fingers available for typing, or using one's mouth to hold a pen, or being able to look at screens for only an hour per day, or processing written information better than aural or the other way around-- all of those differences from the presumed norm mean that...the work is done in different temporalities. A common complaint is that those using AAC wished for more time in 
conversations so that the discourse could accommodate their voices (Ashby \& CaustonTheoharis 2012).

Abled people do not realize nor do they consider what normative expectations costs people in terms of language learning, building relationships, and self actualization amongst disabled people. Disabled people manifest this loss as a collective grief. They grieve language they didn't have access to and couldn't learn, or struggled with people's impatience with us and reluctance to go slow, to repeat, to gesture, and the costs of impatience with communications (Brueggemann 1997; Price 2021).

What expansive potentialities might we discover in the stretch of patience in languaging with each other? Like Kusters (2017) demonstrated in her study of translanguaging in India, people invested in mutual understanding, e.g. through gesture-based conversation, would be willing to repeat their utterances or the other person's utterances. Several repetitions might be required to achieve understanding. Sometimes repetition is accompanied by guesswork, search sequences, language games, and listening for multimodal cues, which can stretch out seemingly brief language exchanges (Goodwin 1995). And as artist Christine Sun Kim puts it, crip time and language, is "punctuated by writing/scrawling questions, in reading, and the creativity in ad-lib responding," (Kim 2021). But the labor in co-constructing meaning, in listening actively, through waiting for interpreters or scrawled words, impatience and instance upon normative language time imposes limits on an interlocutor's agency. Crip language insists that crip time in languaging is vital for a person's agency, be it through interpretation, translation, delayed speech, repetition, gesture, movements in gaze, and prosodic changes. Language is multimodal, interdependent, and both the user and the listener cannot be separated from the semiotic environment (Goodwin 2004).

Some forms of crip languaging, like signed languages, are capable of conveying multiple layers of information at the same time, bending and contracting time simultaneously, able to communicate information about the past and the future reaching both backward and forward in time. Here crip time relies on the intrinsic multi-modality of languaging, which goes beyond what is possible via speech alone. This simultaneous bending and contraction and explosion of time is best seen in signed language literature (Bauman, Nelson, Rose 2006; Bauman \& Murray 2014). This investment of time, the stretching of time to accommodate communication and understanding, and the ability to transcend national and linguistic boundaries in translanguaging across multiple modalities (Moriarty and Kusters, 2021) offers only small glimpses of the potency of crip languaging.

But as some scholars have reminded us, crip time can also be full of potential, joy, resistance, and agency. The ways disability interacts with time and language can reveal the potency of communication. For example, the benefits of text-based or solely text based communications, as 
demonstrated by DeafBlind people, shows that written language can serve as a stand alone modality for some while offering a full range of benefits. Among those benefits are greater flexibility in how and when to communicate and the ability to slow the speed of communication in real time, which offers opportunities to reflect on what is being said (Friedner, Sanchez, Mills, 2020).

\section{Care work and Interdependence in Crip Languaging}

Crip linguistics shows us what is possible in language brokering and mutual meaning making. One aspect of language brokering is the emphasis on relationship building as a part of the languaging process between disabled people. Like Kusters (2017) writes, once acquaintance was made, "the time and effort communication required diminished: they know what they can expect and a certain schema is in place."

One lesson from crip languaging is the idea of interdependence and forms of access intimacy through the discourse process. And there is evidence that deaf people's communication is driven by an intrinsic moral value to actively understand and be understood using a wide range of semiotic tools across languages (Moriarty and Kusters, 2021).

What is care work in languaging? Care work in languaging is not similar to traditional caregiving but visioned through the framework developed by disability justice activist and author Leah Piepzna-Samarasinha (2018). Linguistic care work is the time taken in being patient, in supporting and providing semiotic resources, in seeking, expanding, and claiming our own semiotic resources, in calibrating to each other in seeking mutual understanding. This is not only language work but care work through languaging in being invested in collective access and belonging. Linguistic care work in the context of disability justice is to work together to create and provide optimal environments and material conditions for language (and mutual understanding) to take place.

Being an interlocutor requires a willingness to listen attentively, parse meaning, and abandon prescriptive ideas about language. Each party in the conversation engages to the best of their ability. Furthermore, each party is an active participant in constructing meaning. The level of effort may vary, but it is never a fully passive process. This recognizes that language "does not stand alone as a self-contained entity, but emerges from, and is situated within, the talk of others, to which it is inextricably linked," (Goodwin 1995). In fact, if the interlocutors are cooperative, they can co-construct meaning through the use of others' speech. Linguistic anthropologist Charles Goodwin notes that a man with aphasia, Rob, who was only able to speak three words, was able to engage in complicated language by using resources provided by the speech of others. Rob was able to participate in conversation through talk-interaction, pointing, and using varied intonations (Goodwin 1995). Embracing language as an intimate process grounded in a desire to mutually understand one another, rather than label such work as disordered communication, 
means labeling communication aids, including language games and sign language interpretation, as natural aspects of languaging and human communication. As Goodwin frames it, a speaker "requires a larger social and semiotic matrix that encompasses the bodies, talk, and actions of others, as well as the way in which they are situated within a particular historical, social, and material environment (Goodwin 2004). Those games and interactions between Goodwin's subjects, Rob and Chil and their respective families and caretakers are good examples of linguistic care work.

Crip Linguistics is therefore about putting the people back in languaging and recognizing that analyzing languaging without considering the languagers separates the language from the work that people put into producing them, especially via disabled bodies. Relationships, as an extension of interdependence, emphasizes that crip languaging is more valued by disabled people because of the effort and work involved (Green 2014). This is also a form of access intimacy. Mia Mingus in Hamraie and Fritsch (2019) describes access intimacy as a "crip relational practice produced when interdependence informs the making of access." As such, interdependent ways of languaging, like augmented speech, do not appeal to many abled people. For example, as Mackay's work with aphasia patients showed, the patients were viewed as incompetent because of their voicelessness. Given an acceptance of interdependence and care work in languaging via crip time, the patients would be viewed as competent (Rossetti, et al. 2008).

\section{Conclusion}

Hamraie (2013) asks us to think about the politics of access through the framework of interdependence. Languaging, as an important site of access- to the world, to politics, to belonging, to citizenship, thus demands that we think about this through the lens of collective access and care. Rejecting monolingualism and monomodality are two beginning steps. Embracing time, space, and material environments in meaning-making are also preliminary steps. Interdependence also asks us to think about our built environments and how that impacts access (Hamraie 2013)- and in our case- language. Hamraie and Fritsch (2019)'s practices of "interdependence, access intimacy, and collective access can be understood as alternative political technologies through Crip technoscience. Crip technoscience is "critique, alteration, and reinvention." It is how disabled people alter and reinvent the world in order to make access happen. The relationship between science, technology, and language is such that the dismissal of disabled ways of languaging has resulted in inaccessible technologies.

What's next, then? We invite theoretical and applied linguists to use crip linguistics, in some cases, via disidentification.

Disidentification describes identifying with but not as a member of another marginalized group (Schalk 2013). In identifying with but not as, one recognizes that they are "implicated by the culture and politics of another group and seek to better understand this link." Schalk urges us to 
think of disidentification as a "careful, conscious joining- a standing/sitting among rather than by or behind a group." We invite linguists across socio, queer, trans, and racio linguistics to seek ways to identify with crip linguistics. What are our similarities and overlaps? What do we bring to each other in our interrogations and frameworks? In the places where those disidentification occurs across/between/among minoritized subjects, how might we develop coalitional theories that are attentive to a variety of marginalized groups? We want to think about how the logics that uphold ideas about disordered languaging is rooted in racism, accentism, in sounding a certain way- in communicating and languaging in certain ways- and how those logics are similar and overlapping. In disidentification within linguistics- as queer, trans, gendered, disabled, and racialized languaging- can we seek the ways in which they overlap in terms of being characterized as disordered- and how languages characterized as disordered are marginalized, belittled, disregarded.

On contrary to what people believed of Helen Keller's languaging capacity (and the contributions of theoretical linguists to this chauvinism), contemporary DeafBlind poet and essayist John Lee Clark has written about distanism and the philosophy of ProTactile. Clark's description of meetings of DeafBlind people reveals a world of co-constructed meaning, mutual misunderstanding as Pennycook (2018) describes, bent and stretched and manipulated time, sensory orientations and translanguaging, the morality of language calibration and mutual understanding as care work for access and practices of access intimacy, adaptions of technology, and relationality. To sum, disabled people do really cool things with language if linguists would pay attention.

\section{Acknowledgements}

Lynn Hou. It was her tweet that started this. Thanks for prompting us to have this conversation. Erin Moriarty Harrelson, many thanks for the articles, encouragement, and comments on early drafts. Much gratitude to Emily Carrigan, Megan Figueroa, and Aparna Nair for editing and early commentary as well as personal conversations. To our disabled communities for their crip wisdom and joy. 


\section{References}

Alland, Sandra. Eli Clare on our relationship with "abnormal" and the promise of cure-Disability Arts Online. (n.d.). Retrieved April 5, 2021, from

https://disabilityarts.online/magazine/opinion/eli-clare-relationship-abnormal-promise-cure/

Anderson, Catherine. 2018. Essentials of Linguistics.

https://ecampusontario.pressbooks.pub/essentialsoflinguistics/

Annamma, Subini A., Amy L. Boelé, Brooke A. Moore \& Janette Klingner. 2013. Challenging the ideology of normal in schools. International Journal of Inclusive Education 17(12). 1278-1294. DOI: https://doi.org/10.1080/13603116.2013.802379

Annamma, Subini \& Deb Morrison. 2018. Identifying Dysfunctional Education Ecologies: A DisCrit Analysis of Bias in the Classroom. Equity \& Excellence in Education 51(2). 114-131. DOI: https://doi.org/10.1080/10665684.2018.1496047

Antia, Shirin D., Patricia Jones, John Luckner, Kathryn H. Kreimeyer \& Susanne Reed. 2011. Social outcomes of students who are deaf and hard of hearing in general education classrooms. Exceptional Children 77(4). 489-504. DOI: https://doi.org/10.1177/001440291107700407

Ashby, Christine E. \& Julie Causton-Theoharis. 2012. "Moving quietly through the door of opportunity": Perspectives of College Students who Type to Communicate. Equity \& Excellence in Education 45(2). 261-282. DOI: https://doi.org/10.1080/10665684.2012.666939

Ashley, Florence., 2020. A critical commentary on 'rapid-onset gender dysphoria'. The Sociological Review, 68(4), pp.779-799.https://doi.org/10.1177/0038026120934693

Baker-Bell, April. 2019. Dismantling anti-black linguistic racism in English language arts classrooms: Toward an anti-racist black language pedagogy. Theory Into Practice 1-14. DOI: https://doi.org/10.1080/00405841.2019.1665415

Bauman, H.-Dirksen L. 2004. Audism: Exploring the metaphysics of oppression. Journal of Deaf Studies and Deaf Education 9(2). 239-246. DOI: https://doi.org/10.1093/deafed/enh025

Bauman, H.-Dirksen, Jennifer Nelson, \& Heidi Rose. 2006. Signing the body poetic: Essays on American Sign Language literature. Berkeley: University of California Press.

Bauman, H.-Dirksen. 2007. On the disconstruction of (sign) language in the Western Tradition: A Deaf Reading of Plato's Cratylus," In H-Dirkson Bauman. (Ed.) Open your eyes: Deaf studies talking. 127-145. University of Minnesota Press.

Bauman, H-Dirksen, \& Joseph Murray. 2014.. Deaf gain: Raising the stakes for human diversity. University of Minnesota Press. https://doi.org/10.5749/j.ctt9qh3m7 
Baynton, Douglas. 1996. Forbidden Signs: American Culture and the Campaign Against Sign Language. University of Chicago Press.

Baynton, Douglas. 2001. Disability and the justification of inequality in American history. In P.K. Longmore \& L. Umansky (eds.), The new disability history. New York University Press.

Bender, Emily M., Timnit Gebru, Angelina McMillan-Major \& Shmargaret Shmitchell. 2021. On the Dangers of Stochastic Parrots: Can Language Models Be Too Big? \&. In Proceedings of the 2021 ACM Conference on Fairness, Accountability, and Transparency, 610-623. Virtual Event Canada: ACM. DOI: https://doi.org/10.1145/3442188.3445922

Bergen, Benjamin. 2012. Louder than words: The new science of how the mind makes meaning. Basic Books.

Berger, James. 2014. The Disarticulate: Language, Disability, and the Narratives of Modernity. NYU Press.

Berko-Gleason, Jean \& Nan Bernstein. 2017. The development of language. 9th Edition. Pearson.

Berne, Patricia, Aurora Levins Morales, David Langstaff, and Sins Invalid. 2018. "Ten Principles of Disability Justice." WSQ: Women's Studies Quarterly 46, no. 1. 227-230. doi:10.1353/wsq.2018.0003.

Bickerton, Derek. 2009. Adam's tongue: how humans made language, how language made humans. Macmillan.

Bishop, D.V.M. 1992. The Underlying Nature of Specific Language Impairment. Journal of Child Psychology and Psychiatry 33(1). 3-66. DOI: https://doi.org/10.1111/j.14697610.1992.tb00858.x

Block, David. 2015. Social Class in Applied Linguistics. Annual Review of Applied Linguistics 35. 1-19. DOI: https://doi.org/10.1017/S0267190514000221

Blommaert, Jan. 2005. Discourse: A critical introduction. Cambridge University Press.

Bolinger, Dwight L. 1946. Thoughts on 'Yep' and 'Nope. American Speech 21(2). 90. DOI: https://doi.org/10.2307/486479

Bradbury, Jill Marie, John Lee Clark, Jason Herbers, Victoria Magliocchino, Jasper Norman, Yashaira Romilus \& Robert T. Sirvage. 2019. ProTactile Shakespeare: Inclusive Theater by/for the DeafBlind. Shakespeare Studies, 47, 81-115. 
Brueggemann, Brenda. 1997. On (almost) passing. College English, 59(6), 647-660. doi:10.2307/378278

Bucholtz, Mary. 2003. Sociolinguistic nostalgia and the authentication of identity. Journal of Sociolinguistics 7(3). 398-416. DOI: https://doi.org/10.1111/1467-9481.00232

Burch, Susan, and Hannah Joyner. 2007. Unspeakable: The story of Junius Wilson. University of North Carolina Press.

Burke, Meredith. 2018. Message posted to ASL THAT! https://www.facebook.com/groups/ASLTHAT/permalink/2125258817705614/

Calder, Jeremy. 2020. From “Gay Lisp” to “Fierce Queen”: The Sociophonetics of Sexuality's Most Iconic Variable. In J. Calder, Kira Hall \& Rusty Barrett (eds.), The Oxford Handbook of Language and Sexuality,. Oxford University Press. DOI: https://doi.org/10.1093/oxfordhb/9780190212926.013.49

Charity-Hudley, Anne. In Prep. The lung. In Mary Bucholtz and Kira Hall. Eds. Parsing the body: Language and the social life of Embodiment.

Cioè-Peña, María. 2020. Raciolinguistics and the Education of Emergent Bilinguals Labeled as Disabled. The Urban Review. DOI: https://doi.org/10.1007/s11256-020-00581-z

Clare, Eli. 2017. Brilliant imperfection: Grappling with cure. Duke University Press.

Clark, John., \& Jelica Nucci. 2020. Protactile Linguistics: Discussing recent research findings. Journal of American Sign Languages and Literatures.https://www.youtube.com/watch?v=vfICNTq6ITY accessed April 6, 2021.

Cohn, Neil. 2019. Visual narratives and the mind: Comprehension, cognition, and learning. In Psychology of Learning and Motivation, Vol. 70, 97-127. Elsevier. DOI: https://doi.org/10.1016/bs.plm.2019.02.002

Crow, Liz. 2010. Including All of Our Lives: Renewing the social model of disability. Equatity, Participation and Inclusion 1: Diverse Perspectives (1996). 124-140. DOI: https://doi.org/10.1017/CBO9781107415324.004

Crowe, Kathryn, Marc Marschark, Jesper Dammeyer \& Christine Lehane. 2017. Achievement, Language, and Technology Use Among College-Bound Deaf Learners. The Journal of Deaf Studies and Deaf Education 22(4). 393-401. DOI: https://doi.org/10.1093/deafed/enx029

Dellert, Johannes, Thora Daneyko, Alla Münch, Alina Ladygina, Armin Buch, Natalie Clarius, ... Gerhard Jäger. 2020. NorthEuraLex: a wide-coverage lexical database of Northern Eurasia. 
Language Resources and Evaluation 54(1). 273-301. DOI: https://doi.org/10.1007/s10579-019$\underline{09480-6}$

Dolmage, Jay. 2011. Disabled upon arrival: The rhetorical construction of disability and race at Ellis Island. Cultural Critique 77 (Winter 2011), 24-69.

Edwards, R. A. R. 2012. Words made flesh: Nineteenth-Century deaf education and the growth of deaf culture. NYU Press.

Edwards, Terra. (2018). Re-channeling language: The mutual restructuring of language and infrastructure among DeafBlind people at Gallaudet University. Journal of Linguistic Anthropology, 28(3), 273-292. https://doi.org/10.1111/jola.12199

Flores, Nelson \& Jonathan Rosa. 2015. Undoing Appropriateness: Raciolinguistic Ideologies and Language Diversity in Education. Harvard Educational Review 85(2). 149-171. DOI: https://doi.org/10.17763/0017-8055.85.2.149

Figueroa, Megan \& Carrie Gillion. 2018. Vocal Fries. A Podcast

Fisher, Amy, Benjamin W. Fisher \& Kirsten S. Railey. (2020.) Disciplinary disparities by race and disability: using DisCrit theory to examine the manifestation determination review process in special education in the United States, Race Ethnicity and Education, DOI:

$\underline{10.1080 / 13613324.2020 .1753671}$

Friedner, Michelle., \& Pamela Block. 2017. Deaf studies meets autistic studies. Senses \& Society, 12(3), 282-300. https://doi.org/10.1080/17458927.2017.1369716

Ganz, Jennifer B. 2015. AAC interventions for individuals with Autism Spectrum Disorders: State of the science and future research directions. Augmentative and Alternative Communication 31(3). 203-214. DOI: https://doi.org/10.3109/07434618.2015.1047532

Goodwin, Charles. 1995. Co-constructing meaning in conversations with an aphasic man. Research on Language and Social Interaction. 28(3), 233-260.

Goodwin, Charles. 2004. A competent speaker who can't speak: The social life of aphasia. Journal of Linguistic Anthropology, 14(2), 151-170.

http://dx.doi.org.proxyga.wrlc.org/10.1525/jlin.2004.14.2.151

Grech, Shaun., \& Karen Soldatic. 2015. Disability and colonialism: (Dis)encounters and anxious intersectionalities. Social Identities, 21(1), 1-5. https://doi.org/10.1080/13504630.2014.995394

Green, E Mara. 2014. Building the tower of Babel: International Sign, linguistic commensuration, and moral orientation. Language in Society, 43(4), 445-465. doi:10.1017/S0047404514000396 
Grushkin, Donald A. 2017. Writing signed languages: What for? What form? American Annals of the Deaf 161(5). 509-527. DOI: https://doi.org/10.1353/aad.2017.0001

Hall, Wyatte C., Leonard L. Levin \& Melissa L. Anderson. 2017. Language deprivation syndrome: a possible neurodevelopmental disorder with sociocultural origins. Social Psychiatry and Psychiatric Epidemiology 0(0). 0. DOI: https://doi.org/10.1007/s00127-017-1351-7

Hall, Matthew L., Wyatte C. Hall \& Naomi K. Caselli. 2019. Deaf children need language, not (just) speech. First Language 39(4). 367-395. DOI: https://doi.org/10.1177/0142723719834102

Hall, Matthew L., Inge-Marie Eigsti, Heather Bortfeld \& Diane Lillo-Martin. 2016. Auditory Deprivation Does Not Impair Executive Function, But Language Deprivation Might: Evidence From a Parent-Report Measure in Deaf Native Signing Children. Journal of Deaf Studies and Deaf Education (1917). enw054. DOI: https://doi.org/10.1093/deafed/enw054

Hamraie, Aimi. 2013. "Designing collective access: A feminist disability theory of universal design." Disability Studies Quarterly 33.4

Hamraie, Aimi., \& Kelly Fritsch, K. 2019. Crip technoscience manifesto. Catalyst: Feminism, Theory, Technoscience, 5(1), 1-33. https://doi.org/10.28968/cftt.v5i1.29607

Hart, Betty, and Todd R. Risley. 2003. The early catastrophe: The 30 million word gap by age 3 . American Educator 27.1 4-9.

Healey, Katherrine Heather Rae. 2019. Lending their ears: Hearing, deafness, and aural citizenship in World War II America (Publication No. 13809875) [Yale University]. ProQuest Dissertations and Theses Global.

Henner. Jon., \& Octavian Robinson. 2021. Signs of oppression in the academy: The case of signed languages. In Gail. Clements and Marney. Petray (Eds.). Linguistic Discrimination in US Higher Education: Power, Prejudice, Impacts. 92-110. Routledge.

Hill, Joseph. 2012. Language attitudes in the American deaf community. Gallaudet University Press,

Hill, Joseph C. 2017. The Importance of the Sociohistorical Context in Sociolinguistics : The Case of Black ASL. Sign Language Studies 18(1). 41-57.

Holmes, Jessica A. 2019. The "Manic Pixie Dream Girl of the Synth-Pop World" and Her "Baby Doll Lisp". Journal of Popular Music Studies 31(1). 131-156. DOI:

https://doi.org/10.1525/jpms.2019.311011 
Hoff, Erika, Michelle K. Tulloch \& Cynthia Core. 2021. Profiles of minority-majority language proficiency in 5-Year-Olds. Child Development cdev.13591. DOI:

https://doi.org/10.1111/cdev.13591

Hou, Lynn \& Annelies, Kusters. 2020. Sign languages. In Karin Tusting. (Ed.) The routledge handbook of linguistic ethnography, 340-355. Routledge.

Kim, Christine Sun. 2019. spoken on my behalf. [Three channel video, 43:18. Text, images, and sound files.] retrieved from http://christinesunkim.com/work/spoken-on-my-behalf/

Kusters, Annelies. 2015. Deaf space in Adamorobe: An ethnographic study in a village in Ghana. Gallaudet University Press.

Kusters, Annelies \& Lynn Hou. 2020. Linguistic Ethnography and Sign Language Studies. Sign Language Studies 20(4). 561-571. DOI: https://doi.org/10.1353/sls.2020.0018

Kusters, Annelies, Massimiliano Spotti, Ruth Swanwick \& Elina Tapio. 2017. Beyond languages, beyond modalities: transforming the study of semiotic repertoires. International Journal of Multilingualism 14(3). 219-232. DOI: https://doi.org/10.1080/14790718.2017.1321651

Labov, William. 1972. Language in the inner city: Studies in the Black English vernacular. No. 3. University of Pennsylvania Press.

Ladd, Paddy. 2003. Understanding deaf culture. Multilingual Matters,

Lane, Harlan. 1976. The Wild Boy of Aveyron. Harvard University Press.

Leonardo, Zeus \&Alicia Broderick. 2011. Smartness as Property: A Critical Exploration of the Intersections between Whiteness and Disability. Teachers College Record, 113 (10): 2206-32.

Linguistics Society of America (2021). What is linguistics?. Retrieved from https://www.linguisticsociety.org/what-linguistics

Livingston, Julie. 2006. Insights from an African History of Disability. Radical History Review, 2006(94), 111-126. https://doi.org/10.1215/01636545-2006-94-111

Manfredi, Mirella, Neil Cohn, Pamella Sanchez Mello, Elizabeth Fernandez \& Paulo Sergio Boggio. 2020. Visual and Verbal Narrative Comprehension in Children and Adolescents with Autism Spectrum Disorders: An ERP Study. Journal of Autism and Developmental Disorders 50(8). 2658-2672. DOI: https://doi.org/10.1007/s10803-020-04374-x

Marshall, Caitlin. 2014. Crippled Speech. Postmodern Culture: A Journal of Interdisciplinary Thought in Contemporary Cultures. 24 (3), Retrieved March 6, 2021, from http://www. pomoculture.org/2017/09/09/crippled-speech/\# edn5 
McCulloch, Gretchen. 2020. Because internet: Understanding the new rules of language. Riverhead Books.

McRuer, Robert. 2006. Crip theory: Cultural signs of queerness and disability. NYU Press.

McRuer, Robert.2010. Disability Nationalism in Crip Times. Journal of Literary \& Cultural Disability Studies, vol. 4 no. 2, 2010, p. 163-178. Project MUSE muse.jhu.edu/article/390397.

Merrell, Floyd. 2016. Peirce, signs, and meaning. University of Toronto Press,

Mondellli, Frank. 2021. "How the hearing aid molded a regime of rhythm in Japan," Society for Cinema and Media Studies, Chicago, IL. 2021.

Moriarty Harrelson, Erin. 2019. Deaf people with "no language": Mobility and flexible accumulation in languaging practices of deaf people in Cambodia. Applied Linguistics Review 0(0). DOI: https://doi.org/10.1515/applirev-2017-0081

Moriarty, Erin \& Annelies Kusters. 2021. Deaf cosmopolitanism: calibrating as a moral process, International Journal of Multilingualism, DOI: 10.1080/14790718.2021.1889561

Nair, Aparna. 2020. Technologies for the deaf in British India, 1850-1950. In. Bess Williamson \& Elizabeth Guffey. (Eds). Making disability modern: Design Histories. 77-94. Bloomsbury.

Onion, Rebecca. 2021, February 26. Did Helen Keller Really “Do All That”? Slate Magazine.https://slate.com/human-interest/2021/02/helen-keller-tiktok-conspiracy.htm

Paul, Rhea, Courtnenay Norbury, \& Carolyn Gosse. 2018. Language disorders from infancy through adolescence: Listening, speaking, reading, writing, and communicating. (5th edition). Mosby. https://doi.org/10.1016/C2015-0-04093-X

Pennycook, Alastair. 2010. Critical and alternative directions in applied linguistics. Australian Review of Applied Linguistics 33(2). 16.1-16.16. DOI: https://doi.org/10.2104/aral1016

Pennycook, Alastair. 2018. Posthumanist applied linguistics. Applied Linguistics. 39 (4), 445461. doi:10.1093/applin/amw016

Pennycook, Alastair. 2021. Critical applied linguistics: A critical re-introduction. 2nd Edition. Routledge.

Perniss, Pamela. 2018. Why we should study multimodal language. Frontiers in Psychology 9. 1109. DOI: https://doi.org/10.3389/fpsyg.2018.01109 
Petitto, Laura Ann. 2000. On the biological foundations of human language. In Karen Emmorey \& Harlan Lane (Eds). The Signs of Language Revisited: An Anthology to Honor Ursula Bellugi and Edward Klima. 449-473. Psychology Press.

Piepzna-Samarasinha, Leah Lakshmi. 2018. Care work: Dreaming disability justice. Arsenal Pulp Press.

Piller, Ingrid. 2020. Language and social justice. In James Stanlaw (ed.), The International Encyclopedia of Linguistic Anthropology, 1st ed. Wiley. DOI:

https://doi.org/10.1002/9781118786093

Percy-Smith, Lone, Tenna Lindbjerg Tønning, Jane Lignel Josvassen, Jeanette Hølledig Mikkelsen, Lena Nissen, Eveline Dieleman, ... Per Cayé-Thomasen. 2018. Auditory verbal habilitation is associated with improved outcome for children with cochlear implant. Cochlear Implants International 19(1). 38-45. DOI: https://doi.org/10.1080/14670100.2017.1389020

Price, Margaret \& Stephanie L. Kerschbaum. 2016. Stories of Methodology: Interviewing Sideways, Crooked and Crip. Canadian Journal of Disability Studies 5(3). 18. DOI: https://doi.org/10.15353/cjds.v5i3.295

Price, Margaret. 2015. The Bodymind Problem and the Possibilities of Pain. Hypatia 30(1). 268284. DOI: https://doi.org/10.1111/hypa.12127

Ramjattan, Vijay A. 2020. Engineered accents: international teaching assistants and their microaggression learning in engineering departments. Teaching in Higher Education 1-16. DOI: https://doi.org/10.1080/13562517.2020.1863353

Rickford, John R. \& Sharese King. 2016. Language and linguistics on trial: Hearing Rachel Jeantel ( and other vernacular speakers ) in the courtroom and beyond. Language 92(4). 948988.

Robinson, Octavian. 2010. "We are of a different class": Ableist rhetoric in deaf America, 18801920." Deaf and disability studies: Interdisciplinary perspectives.: 5-21.

Rosa, Jonathan \& Nelson Flores. 2017. Unsettling race and language: Toward a raciolinguistic perspective. Language in Society 46(5). 621-647. DOI:

https://doi.org/10.1017/S0047404517000562

Rosa, Jonathan. 2019. Looking like a language, sounding like a race. Oxford

Rossetti, Zachary, Christine Ashby, Katrina Arndt, Marilyn Chadwick \& Maho Kasahara. 2008. "I Like Others to Not Try to Fix Me": Agency, independence, and Autism. Intellectual and Developmental Disabilities 46(5). 364-375. DOI: https://doi.org/10.1352/2008.46:364-375 
Samuels, Ellen. 2017. Six ways of looking at Crip Time. Disability Studies Quarterly, 37(3), Article 3. https://doi.org/10.18061/dsq.v37i3.5824

Samuels, Ellen \& Elizabeth Freeman. 2021. Introduction: Crip temporalities. South Atlantic Quarterly 120(2). 245-254. DOI: https://doi.org/10.1215/00382876-8915937

Sandahl, Carrie. 2003. Queering the crip or cripping the queer?: Intersections of queer and qrip Identities in solo autobiographical performance. GLQ: A Journal of Lesbian and Gay Studies, 9(1), 25-56.DOI: https://doi.org/10.1215/10642684-9-1-2-25

Schalk, Sami. 2018. Bodyminds Reimagined: (Dis)ability, Race, and Gender in Black Women's Speculative Fiction. Duke University Press.

Schalk, Sami. 2013. Coming to Claim Crip: Disidentification with/in Disability Studies. Disability Studies Quarterly, 33(2), Article 2. https://doi.org/10.18061/dsq.v33i2.3705

Scott, Jessica A. \& Jonathan Henner. 2020. Second verse, same as the first: On the use of signing systems in modern interventions for deaf and hard of hearing children in the USA.

Deafness \& Education International 1-19. DOI: https://doi.org/10.1080/14643154.2020.1792071

Soto, Gloria \& Wendy Olmstead. 1993. A semiotic perspective for AAC. Augmentative and Alternative Communication 9(2). 134-141. DOI:

https://doi.org/10.1080/07434619312331276521

Sun, Lei \& Geraldine P. Wallach. 2014. Language disorders are learning disabilities: Challenges on the divergent and diverse paths to language learning disability. Topics in Language

Disorders 34(1). 25-38. DOI: https://doi.org/10.1097/TLD.0000000000000005

Titchkosky, Tanya. 2001. From the field -- coming out disabled: The politics of understanding. Disability Studies Quarterly, 21(4), Article 4. https://doi.org/10.18061/dsq.v21i4.325

Thompson, Bill, Seán G. Roberts \& Gary Lupyan. 2020. Cultural influences on word meanings revealed through large-scale semantic alignment. Nature Human Behaviour 4(10). 1029-1038. DOI: https://doi.org/10.1038/s41562-020-0924-8

Tuttleturtle. 2020. My AAC is part of my gender presentation. https://presenters.aacconference.com/videos/U1RVMVFUSXc

Quittner, Alexandra L., David H. Barker, Ivette Cruz, Carolyn Snell, Mary E. Grimley, Melissa Botteri, \& CDaCl Investigative Team. 2010. Parenting stress among parents of deaf and hearing children: Associations with language delays and behavior problems. Parenting 10(2). 136-155. DOI: https://doi.org/10.1080/15295190903212851 
Valente, Joseph Michael. 2011. Cyborgization: Deaf education for young children in the cochlear implantation era. Qualitative Inquiry 17(7). 639-652. DOI:

https://doi.org/10.1177/1077800411414006

Valente, Joseph Michael \& Gail Boldt. 2016. The curious case of the deaf and contested landscapes of bilingual education. Equity \& Excellence in Education 49(3). 336-349. DOI: https://doi.org/10.1080/10665684.2016.1194101

Van Borsel, John, Els De Bruyn, Evelien Lefebvre, Anouschka Sokoloff, Sophia De Ley \& Nele Baudonck. 2009. The prevalence of lisping in gay men. Journal of Communication Disorders 42(2). 100-106. DOI: https://doi.org/10.1016/j.jcomdis.2008.08.004

Vaughn-Cooke, A. Fay. 2007. Lessons learned from the Ebonics controversy: Implications for language assessment. In Robert Bayley \& Ceil Lucas. (Eds). Sociolinguistic variation: Theories, methods, and applications. 254 - 275.Cambridge.

Virdi, Jai. 2020. Hearing happiness: Deafness cures in history. University of Chicago Press.

von Tetzchner, Stephen. 2015. The semiotics of aided language development. Cognitive Development 36. 180-190. DOI: https://doi.org/10.1016/j.cogdev.2015.09.009

Walle, Eric A. \& Joseph J. Campos. 2014. Infant language development Is related to the acquisition of walking. Developmental Psychology 50(2). 14. DOI:

https://doi.org/10.1037/a0033238

Yamasaki, Brianna L. \& Gigi Luk. 2018. Eligibility for Special Education in Elementary School: The Role of Diverse Language Experiences. Language, Speech, and Hearing Services in Schools 49(4). 889-901. DOI: https://doi.org/10.1044/2018 LSHSS-DYSLC-18-0006

Zimman, Lal. 2019. Trans self-identification and the language of neoliberal selfhood: Agency, power, and the limits of monologic discourse. International Journal of the Sociology of Language 2019(256). 147-175. DOI: https://doi.org/10.1515/iisl-2018-2016 